TPeriodica Polytechnica Civil Engineering

\author{
62(2), pp. 337-345, 2018 \\ https://doi.org/10.3311/PPci.11450 \\ Creative Commons Attribution (1)
}

RESEARCH ARTICLE

\section{Static and Dynamic Analysis of Cracked Concrete Beams Using Experimental Study and Finite Element Analysis}

\author{
Hamid Mazaheri ${ }^{1}$, Hossein Rahami ${ }^{2}$, Ali Kheyroddin ${ }^{3}$
}

Received 04 September 2017; Revised 16 October 2017; Accepted 24 October 2017

\begin{abstract}
In this paper, a simple method for defining the effects of cracks on elastic behavior of beam is presented. The cracked sections were modelled as rotational springs and the problem was solved using the finite element method. The global stiffness matrix of a beam with multiply cracked section was then assembled. For calculation of rotational spring stiffness equivalent to uncracked and cracked sections, finite element models and experimental test were used.

The natural frequencies and mode shape of beams with multiple single-edge cracks were obtained and a new simple formula was proposed. Published numerical examples for cracked beams were used for validation.
\end{abstract}

\section{Keywords}

crack, rotational spring, dynamic parameter, concrete beam, modal analysis, bending rigidity

\footnotetext{
1 Department of Civil Engineering, Islamic Azad University,

Arak Branch, Arak, Iran

2 School of Engineering Science, College of Engineering,

University of Tehran, Tehran, Iran

3 Department of civil Engineering, Semnan University, Semnan, Iran

* Corresponding author, email: hrahami@ut.ac.ir
}

\section{Introduction}

The occurrence of cracks in reinforced concrete elements is expected under service loads, due to the low tensile strength of concrete, weathering, creep and aging effects. Cracking in reinforced concrete structures has an effect on structural performance including stiffness, energy absorption, capacity and ductility. Reduction in the strength and stiffness properties of a structure can be dangerous and may lead to catastrophic structural failures. The effect of the location and depth of cracks on the static and dynamic behavior of concrete structural element has been the subject of several studies and investigations.

One of the first studies on crack detection is that of Adams et al. [1]. Cawley and Adams combined sensitivity and finite element method to determine crack location and depth [1]. Gudnundson in their investigation, used perturbation as well as transfer matrix method to study the influence of small cracks on the Eigen frequencies and modes of slender structures [2] Chang and Petroski used transverse vibrations of a simply supported beam for the detection of location and depth of crack [3]. Qian et al. used a finite element model to determine the natural frequencies of a cantilevered beam, taking into account, the effect of crack closure. Also, a method based on the relationship between the crack and modal parameters was developed to determine the crack position from known natural frequencies [4]. Chondros et al. developed a continuous cracked beam theory for free vibration analysis, their basic assumption was that the crack caused a continuous change in flexibility in its neighbourhood which they modelled by incorporating a consistent displacement field with singularity [5]. A different but related approach in which a crack in rotational shaft is replaced by a massless spring-link located at the crack position, became popular due to much effort by Dimarogonas and Papadopolous [6]. Ostachowicz and Krawczuk, in their studies, analysed the effect of two open cracks on the frequencies of natural flexural vibrations in a cantilever beam [7] Doebling et al. reviewed researches on crack and damage detection and location in structures using vibration data [8]. Salawu reviewed researches on crack detection based on the change in natural frequencies [8]. Kisa et al. in their investigation, 
integrated the finite element method and component mode synthesis and analyzed the vibrational characteristic of cracked Timoshenko beam [9]. Kheyroddin proposed new models for estimating the flexural rigidity and deflection of R.C. beams, to account for the influencing parameters [10]. Ismail et al. determined the location of damage due to single cracks and honeycombs in R.C. beams using mode shape derivatives from modal testing. Experimental modal analysis was performed on beams with cracks prior to and after each load cycle, on a control beam, and beams with honeycombs [11]. Caddemi and Calio used Heaviside and Dirac's delta distribution functions to solve beam vibration problems with multiple open cracks [12]. Kaklauskas et al. proposed a technique for predicting curvatures and crack widths; theirs model was based on a non-iterative algorithm and used a rigid-plastic bond-slip law and elastic properties of materials [13]. Ibrahim et al. used the finite element method to study the effects of crack depth and location on the in-plane free vibration multi-bay and multistore cracked frame structures. Their studies showed that the reduction of natural frequency depends on the crack depth and location and higher drops in the in-plane natural frequency were observed when the crack was located near the roots or corners of the frames [14]. In studies of Labib et al., the rotational spring model was used and natural frequencies of beams and frames with multiple single-edge cracks were obtained $[15,16]$. Aktas and Sumer modelled pre-damaged RC beams in finite element program and indicated that inclusion of predamage levels by means of cracks into the cross sections have significant effect on beams moment capacity [17]. Jena et al. investigated the influence of parameters such as crack depth and crack inclination angles, on the dynamic behaviour of deteriorated structures excited by time-varying mass. Analysis of the structure was carried out at constant transit mass and speed [18]. Akbas and Doguscan studied the static bending of edge cracked micro beams analytically based on modified couple stress theory. The cracked beam was modelled using a proper modification of the classical cracked-beam theory consisting of two sub-beams connected through a massless elastic rotational spring. They determined the deflection curve expressions of the edge cracked microbeam segments separated by rotational spring using the integration method [19].

Eroglu and Tufekci introduced a finite element formulation for straight beams with an edge crack, including the effects of shear deformation and rotatory inertia. The main purpose of these studies is to present a more accurate formulation to improve the beam models used in crack detection problems [20]. In a study by Sabuncu et al., the effects of number of storey, static and dynamic load parameters, crack depth and location on the in-plane static and dynamic stability of cracked multi-storey frame structures subjected to periodic loading were investigated numerically using the Finite Element Method [21].
In this study, the rotational spring model was used and cracks were assumed to be always open, thus, the problem can be described as a linear one.

To confirm the validity and accuracy of the proposed method, a cantilever cracked beam, for which some comparative results were shown by Kisa et al. [9] and Labib et al. [15], was analyzed and the results agrees very well with those of other investigators.

\section{Models of cracks}

A rotational spring model has been used in many studies to identify cracks in beams $[15,22]$ In this study, the cracked beams were modelled by elements and components connected by hinge and massless rotational spring to determine the effects of cracking on bending behavior of beams. As shown in Fig. 1, the Bernoulli-Euler beam is divided into two halves at the crack location. The beam sections are then pinned together and a rotational spring is used to model the increased flexibility due to the crack. It is assumed that the axial stiffness of the beam at the crack location remained intact.

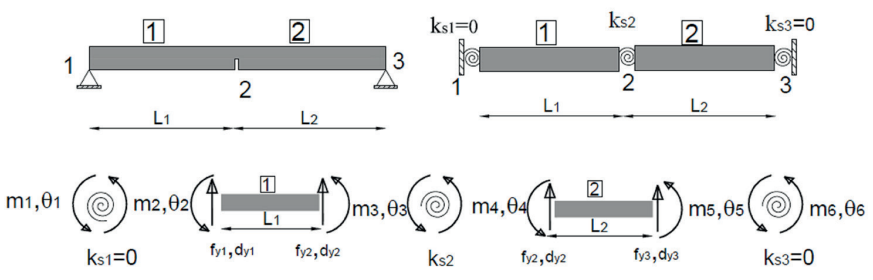

Fig. 1 Bernoulli-Euler cracked beam modelling by rotational spring

It is clear that crack development in every section of the beam results in the whole beam stiffness decrease; the main reason for section stiffness decrease is its effective section height decrease and its moment of inertia. The crack depth increase results in effective section height decrease and section bending rigidity and strain energy of beam decrease. The strain energy is the internal work done by the stress resultants in moving through the corresponding deformations. For the linearly elastic structure the strain energy is equal to complementary strain energy

Here it is assumed that the energy is conserved i.e. the work done by the external force is equal to energy stored in the cracked beam.

In Eq.1, strain energy stored in cracked beam was calculated.

$$
\begin{aligned}
W & =U=U_{b}+U_{s} \\
U_{b} & =\int_{0}^{L} \frac{M(x)^{2}}{2 E I} d x \quad U_{s i}=\frac{1}{2} M_{s i} \theta=\frac{M_{s i}{ }^{2}}{2 k_{s i}} \\
U_{s} & =\sum_{i=1}^{N s} \frac{M_{s i}^{2}}{2 k_{s}} \\
U & =\int_{0}^{L} \frac{M(x)^{2}}{2 E I} d x+\sum_{i=1}^{N s} \frac{M_{s i}^{2}}{2 k_{s i}}
\end{aligned}
$$


Where, $U_{b}$ is strain energy in beam element, $U_{s}$ is strain energy in rotational spring element, $M(x)$ is bending moment loaded on different parts of the beam, $M_{s}$ is bending moment in the location of rotational spring and $k_{s}$ is rotational stiffness of spring.

In the intact beam, the strain energy of beam is

$$
U=U_{b}=\int_{0}^{L} \frac{M(x)^{2}}{2 E I} d x
$$

In this beam there is no strain energy in spring; therefore, the stiffness of rotational spring is $\infty$ theoretically. A crack on a beam introduces considerable local flexibility due to the strain energy concentration in the vicinity of the crack tip under load. In this study, experimental and numerical studies were carried out to determine stiffness of the rotational spring equivalent to cracked section, as discussed below.

\section{Stiffness of rotational spring equivalent to cracked beam section}

To study the effect of cracking on a concrete beam stiffness, experimental samples with rectangular section were built and cracks with different depths were made in them. These samples were loaded in 3 points as shown in Fig. 2, and their loaddisplacement diagrams were plotted. Changes in crack depths result in inclination change of this diagram. Plates with 0.1 $\mathrm{mm}$ thickness were used in two layers to develop cracks in the samples. Therefore, the width of the crack was $0.2 \mathrm{~mm}$. The applied concrete properties are shown in Table 1.

Table 1 Concrete properties of the test beams

\begin{tabular}{lccc}
\hline$f_{c}^{\prime}($ Mpa $)$ & $E_{c}($ Mpa $)$ & $w_{c}\left(\frac{\mathrm{kg}}{\mathrm{m}^{3}}\right)$ & $v$ \\
\hline 0.21 & 2320 & 33200 & 48 \\
\hline
\end{tabular}

The height and wide of the samples are $d=200 \mathrm{~mm}$ and $b=150 \mathrm{~mm}$, respectively, and their length is $L=1000 \mathrm{~mm}$. As shown in Fig. 2, these samples were tested after processing on the $28^{\text {th }}$ day.

After loading, displacement of middle section of the beam was measured and the equivalent stiffness of the beam $\left(k_{e b}\right)$ was calculated. In Eq. 3, strain energy for test sample was calculated.

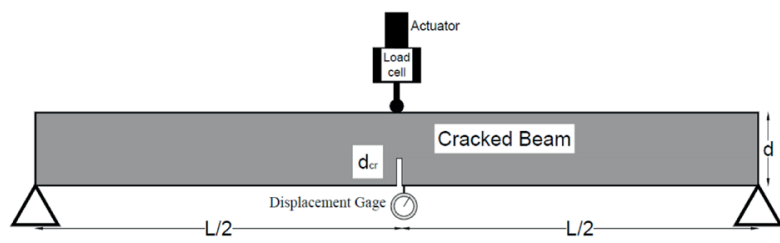

(a)

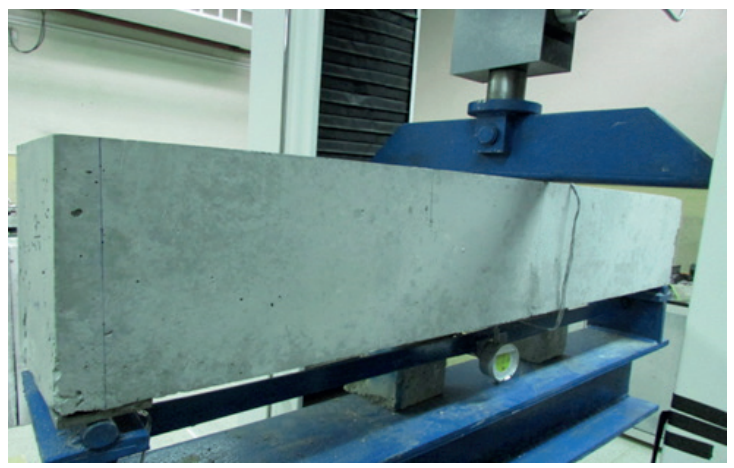

(b)

Fig. 2 Experimental test. a: Test setup b: Test sample

$$
\begin{aligned}
& M(x)=\frac{p}{2} x \quad M_{s}=\frac{P \xi}{2} \quad W=\frac{P \delta}{2} \\
& U=2 \int_{0}^{\frac{L}{2}} \frac{\left(\frac{p}{2} x\right)^{2}}{2 E I} d x+\frac{\left(\frac{P \xi}{2}\right)^{2}}{2 K_{s}}=\frac{P^{2} L^{3}}{96 E I}+\frac{P^{2} \xi^{2}}{8 K_{s}} \\
& W=U \rightarrow \delta=P\left[\frac{L^{3}}{48 E I}+\frac{\xi^{2}}{4 k_{s}}\right]=P\left(\frac{1}{k_{e b}}\right) \Rightarrow \\
& \frac{1}{k_{e b}}=\left(\frac{1}{k_{b}}+\frac{\xi^{2}}{4 k_{s}}\right) \\
& \xi=\frac{L}{2} \Rightarrow \frac{1}{k_{e b}}=\left(\frac{1}{k_{b}}+\frac{L^{2}}{16 k_{s}}\right)
\end{aligned}
$$

$K_{b}$ is stiffness of intact beam and that for test sample is:

$$
K_{b}=\frac{48 E I}{L^{3}}=\frac{48 * 33200 * 1 E 8}{1 E 9}=159360 \mathrm{~N} / \mathrm{mm}
$$

Stiffness of rotational spring equivalent to cracked section in the middle of beams obtained using Eqs. 3 and 4 are presented in Table 2.

In order to complete the required information and control the obtained results, the tested beam was modelled in Abaqus software, and its behavior under 3 point-loading was inves-

\begin{tabular}{|c|c|c|c|c|c|c|c|c|c|}
\hline No & Beam & $h(\mathrm{~mm})$ & $d_{c r}(\mathrm{~mm})$ & $\frac{d_{c r}}{h}$ & $\begin{array}{c}\text { Force of } \\
\text { failure }(N)\end{array}$ & $\begin{array}{l}\text { Displacement } \\
\text { of failure }(\mathrm{mm})\end{array}$ & $\mathrm{N} / \mathrm{mm}$ & $\frac{K_{e b}}{K_{b}}$ & $\begin{array}{c}K_{s} \\
N m m \operatorname{rad}^{-1}\end{array}$ \\
\hline 2 & CB10 & 200 & 20 & 0.1 & 16412 & 0.11 & 149200 & 0.94 & $1.46 \mathrm{E}+11$ \\
\hline 3 & CB20 & 200 & 40 & 0.2 & 15548 & 0.115 & 135200 & 0.85 & $5.57 \mathrm{E}+10$ \\
\hline 4 & CB30 & 200 & 60 & 0.3 & 12965 & 0.120 & 108041 & 0.67 & $2.096 \mathrm{E}+10$ \\
\hline 5 & CB50 & 200 & 100 & 0.5 & 9045 & 0.096 & 94200 & 0.59 & $1.44 \mathrm{E}+10$ \\
\hline
\end{tabular}
tigated. The Abaqus software analysis also shows that. The fracture of the cracked and uncracked beam is illustrated in Fig. 3. Stiffness of rotational spring equivalent to cracked section in the middle section of FE models obtained using Eqs.3 and 4 are presented in Table 3.

Table 2 Stiffness of rotational spring equivalent to cracked section in the experimental samples 
The quality of variation of rotational spring stiffness equivalent to section, according to the crack depth is demonstrated in Fig. 4. The variation of equivalent rotational spring stiffness changes nonlinearly versus the crack depth. It is shown that with the occurrence of a crack in the beam section, the stiffness of the rotational spring decreases dramatically and its effect on stiffness decreases with crack depth increase. According to this diagram, the decrease in spring stiffness versus the crack depth is not linear; on the other hand, the relation is valid in border conditions. If the crack depth is zero, the spring stiffness will tend to infinity and if the crack depth equals the beam height, then its value will be zero. Accordingly, the rotational spring stiffness equivalent to cracked section is suggested as Eq. 5.

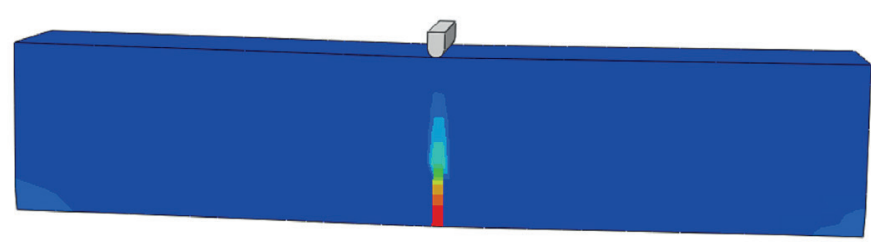

(a)

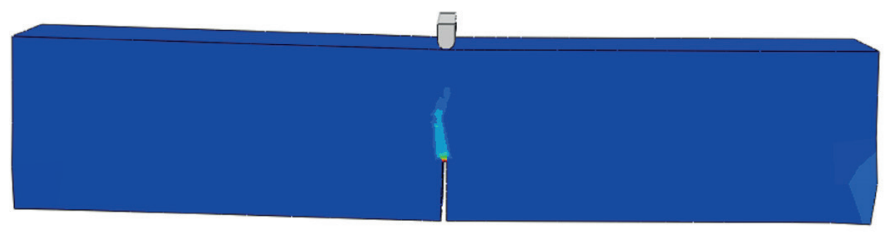

(b)

Fig. 3 The fracture of beam, a: uncracked beam, b: beam with a $20 \mathrm{~mm}$ depth crack

$$
K_{s}=0.70 *\left(\left(\frac{h}{d_{c r}}\right)^{1.2}-1\right) * \frac{E I}{h}
$$

Where $h$ is height of beam section, $d_{c r}$ is depth of crack and EI is bending rigidity of beam section.

Change in the concrete properties during the construction of the samples, due to human error, caused differences in the graphs as shown in Fig. 4.

\section{Stiffness matrix of models}

There are three degrees of freedom $\delta=\left\{\theta_{\mathrm{L}}, \mathrm{d}_{\mathrm{y}}, \theta_{\mathrm{R}}\right\}$ in cracked section of the beam as shown in Fig. 1. $\theta_{\mathrm{L}}$ and $\theta_{\mathrm{R}}$ are rotations at near end of beam elements at the left and right side of rotational spring, respectively, and $d_{y}$ is displacement of node. The stiffness matrix of the cracked beam can be written as Eq. 6. In this matrix, the array corresponding to the displacement of the common point of the beams equals the sum of the stiffness of two beam elements, and the array corresponding to the rotation of the beam elements end adjacent to the middle node equals the sum of the rotational stiffness of the beam and the rotational spring.

\begin{tabular}{|c|c|c|c|c|c|c|c|c|}
\hline .1 & $\mathrm{d}_{\mathrm{y} \mid}$ &, 2 & .3 & $\mathrm{~d}_{\mathrm{y} 2}$ & .4 & .5 & $\mathrm{~d}_{\mathrm{y} 2}$ & .6 \\
\hline$\left[\mathrm{k}_{\mathrm{s} 1}\right.$ & 0 & $-k_{\mathrm{s} 1}$ & 0 & 0 & 0 & 0 & 0 & 0 \\
\hline 0 & $\frac{12 \mathrm{EI}}{\mathrm{L}_{1}^{3}}$ & $\frac{6 \mathrm{EI}}{\mathrm{L}_{1}^{2}}$ & $\frac{6 \mathrm{EI}}{\mathrm{L}_{1}^{2}}$ & $-\frac{12 \mathrm{EI}}{\mathrm{L}_{1}^{3}}$ & 0 & 0 & 0 & 0 \\
\hline$-k_{\mathrm{s} 1}$ & $\frac{6 \mathrm{EI}}{\mathrm{L}_{1}^{2}}$ & $\frac{4 \mathrm{EI}}{\mathrm{L}_{1}}+\mathrm{k}_{\mathrm{s1}}$ & $\frac{2 \mathrm{EI}}{\mathrm{L}_{1}}$ & $-\frac{6 \mathrm{EI}}{\mathrm{L}_{1}^{2}}$ & 0 & 0 & 0 & 0 \\
\hline 0 & $\frac{6 \mathrm{EI}}{\mathrm{L}_{1}^{2}}$ & $\frac{2 \mathrm{EI}}{\mathrm{L}_{1}}$ & $\frac{4 \mathrm{EI}}{\mathrm{L}_{1}}+\mathrm{k}_{\mathrm{s} 2}$ & $-\frac{6 \mathrm{EI}}{\mathrm{L}_{1}^{2}}$ & $-\mathrm{k}_{\mathrm{s} 2}$ & 0 & 0 & 0 \\
\hline 0 & $-\frac{12 \mathrm{EI}}{\mathrm{L}_{1}^{3}}$ & $-\frac{6 \mathrm{EI}}{\mathrm{L}_{1}^{2}}$ & $-\frac{6 \mathrm{EI}}{\mathrm{L}_{1}^{2}}$ & $\frac{12 \mathrm{EI}}{\mathrm{L}_{1}^{3}}+\frac{12 \mathrm{EI}}{\mathrm{L}_{2}^{3}}$ & $\frac{6 \mathrm{EI}}{\mathrm{L}_{2}^{2}}$ & $\frac{6 \mathrm{EI}}{\mathrm{L}_{2}^{2}}$ & $-\frac{12 \mathrm{EI}}{\mathrm{L}_{2}^{3}}$ & 0 \\
\hline 0 & 0 & 0 & $-k_{\mathrm{s} 2}$ & $\frac{6 \mathrm{EI}}{\mathrm{L}_{2}^{2}}$ & $\frac{4 \mathrm{EI}}{\mathrm{L}_{2}}+\mathrm{k}_{\mathrm{s} 2}$ & $\frac{2 \mathrm{EI}}{\mathrm{L}_{2}}$ & $-\frac{6 \mathrm{EI}}{\mathrm{L}_{2}^{2}}$ & 0 \\
\hline 0 & 0 & 0 & 0 & $\frac{6 \mathrm{EI}}{\mathrm{L}_{2}^{2}}$ & $\frac{2 \mathrm{EI}}{\mathrm{L}_{2}}$ & $\frac{4 \mathrm{EI}}{\mathrm{L}_{2}}+\mathrm{k}_{\mathrm{s} 3}$ & $-\frac{6 \mathrm{EI}}{\mathrm{L}_{2}^{2}}$ & $-k_{\mathrm{s} 3}$ \\
\hline 0 & 0 & 0 & 0 & $-\frac{12 \mathrm{EI}}{\mathrm{L}_{2}^{3}}$ & $-\frac{6 \mathrm{EI}}{\mathrm{L}_{2}^{2}}$ & $-\frac{6 \mathrm{EI}}{\mathrm{L}_{2}^{2}}$ & $\frac{12 \mathrm{EI}}{\mathrm{L}_{2}^{3}}$ & 0 \\
\hline 0 & 0 & 0 & 0 & 0 & 0 & $-k_{\mathrm{s} 3}$ & 0 & $\mathrm{k}_{\mathrm{s} 3}$ \\
\hline
\end{tabular}

Where, $k_{s j}$ is stiffness of rotational spring equivalent to cracked section $j, E I$ is bending rigidity, $L_{i}$ is length of element $i$ and $[K]$ is proposed global stiffness matrix.

Global stiffness matrix $[K]$ can be used to obtain the natural frequency and mode shape of undamped beam in free vibration analysis. It is generally known that the Eigen value equation of an undamped structure is as follows:

Table 3 Stiffness of rotational spring equivalent to cracked section in FE models

\begin{tabular}{|c|c|c|c|c|c|c|c|c|c|}
\hline No & Beam & $h(\mathrm{~mm})$ & $b(\mathrm{~mm})$ & $L(\mathrm{~mm})$ & $d_{c r}(\mathrm{~mm})$ & $\frac{d_{c r}}{h}$ & $\begin{array}{c}K_{e b} \\
N / m m\end{array}$ & $\frac{K_{e b}}{K_{b}}$ & $\begin{array}{c}K_{s} \\
N m m \operatorname{rad}^{-1}\end{array}$ \\
\hline 1 & NCB1.0 & 200 & 150 & 1000 & 0 & 0 & 159537 & 1.00 & $\infty$ \\
\hline 2 & NCB1.10 & 200 & 150 & 1000 & 20 & 0.1 & 150900 & 0.947 & $1.77 \mathrm{E}+11$ \\
\hline 3 & NCB1.20 & 200 & 150 & 1000 & 40 & 0.2 & 145350 & 0.91 & $1.03 \mathrm{E} 11$ \\
\hline 4 & NCB1.25 & 200 & 150 & 1000 & 50 & 0.25 & 135740 & 0.85 & $5.72 \mathrm{E} 10$ \\
\hline 5 & NCB1.30 & 200 & 150 & 1000 & 60 & 0.3 & 129630 & 0.81 & $4.34 \mathrm{E}+10$ \\
\hline 6 & NCB1.50 & 200 & 150 & 1000 & 100 & 0.5 & 111100 & 0.69 & $2.28 \mathrm{E}+10$ \\
\hline 7 & NCB2.00 & 300 & 200 & 1000 & 0 & 0 & 714020 & 1 & $\infty$ \\
\hline 8 & NCB2.10 & 300 & 200 & 1000 & 30 & 0.1 & 656827 & 0.916 & $4.88 \mathrm{E}+11$ \\
\hline 9 & NCB2.20 & 300 & 200 & 1000 & 60 & 0.2 & 614252 & 0.857 & $2.68 \mathrm{E}+11$ \\
\hline 10 & NCB2.30 & 300 & 200 & 1000 & 90 & 0.3 & 536740 & 0.748 & $1.33 \mathrm{E}+11$ \\
\hline 11 & NCB2.40 & 300 & 200 & 1000 & 120 & 0.4 & 452582 & 0.631 & $7.67 \mathrm{E}+10$ \\
\hline 12 & NCB2.50 & 300 & 200 & 1000 & 150 & 0.5 & 347883 & 0.485 & $4.22 \mathrm{E}+10$ \\
\hline
\end{tabular}




$$
\left[K-\omega^{2} M\right][\phi]=0
$$

Where $M$ is mass matrix; $K$ is global stiffness matrix, $\omega$ is natural frequency and $\phi$ is mode shape of beam. Matlab code was used to obtain natural frequency and mode shape of beam.

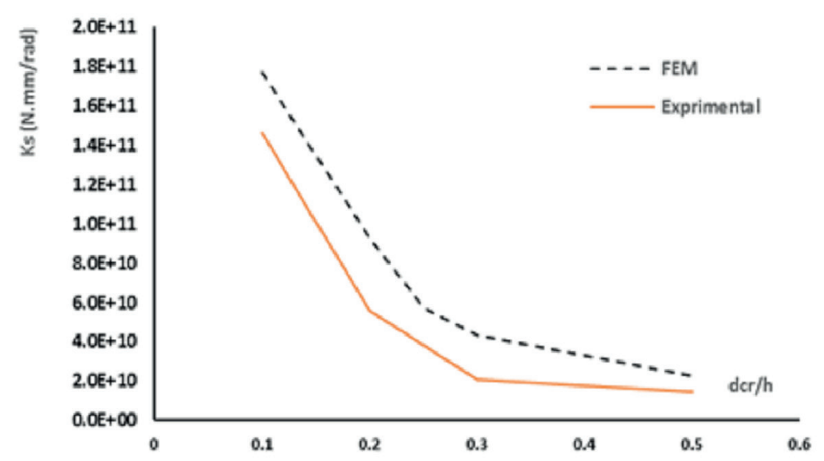

Fig. 4 stiffness of rotational spring stiffness in experimental and FE models

In order to test the accuracy and convergence of the present method, the effects of edge-cracks on the natural frequencies of a cantilever beam that has been studied extensively by Wendtland [23] experimentally and by Gudmundson [2] Kisa et al. [9] and Labib et al. [15] numerically, were examined. The cantilever beam was modeled by rotational spring in cracked section as shown in Fig. 5.

In cracked section, the stiffness of equivalent rotational spring was calculated by Eq. 5, and in uncracked section, it was $\infty$ theoretically. For numerical analysis, it is assumed that $\frac{d_{c r}}{h}=0.01$. Therefore, the stiffness of rotational spring equivalent to intact section can be obtained using Eq. 8 .

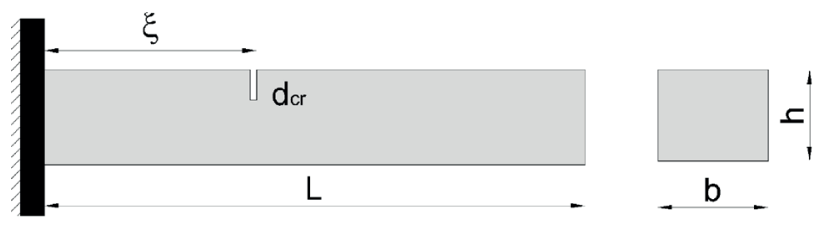

(a)

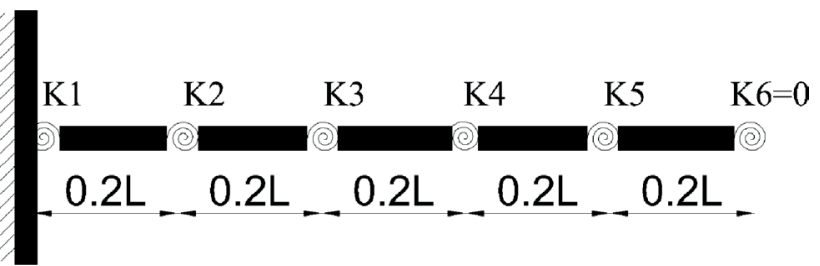

(b)

Fig. 5 Cantilever beam with an edge-crack, a: Geometry b: proposed model

$$
K_{s}=0.70 *\left((100)^{1.2}-1\right) * \frac{E I}{h}=175 . \frac{E I}{h}
$$

The first three natural frequencies of a cantilever beam (Fig. 5) with length of $0.20 \mathrm{~m}$, depth $h=0.0078 \mathrm{~m}$, mass per unit length $\rho=1.5308 \mathrm{~kg} \mathrm{~m}^{-1}$ and bending rigidity $E I=231.548$ N.m ${ }^{2}$ [15], having a single open crack, are shown in Tables 4 to 6. Different variations of the crack to depth ratio $d_{c r} / h$ and crack locations were employed. Eqs. 5 and 6 were used to obtain the equivalent spring stiffness, and global stiffness matrix and natural frequency of beam, respectively. The predicted Eigen frequency changes calculated from the proposed equation were compared with the numerical data obtained by Kisa et al. [9] and Labib et al. [15] for the first three Eigen frequencies.

\begin{tabular}{|c|c|c|c|c|c|c|c|c|c|c|c|}
\hline \multirow{2}{*}{$d_{c r} / h$} & \multicolumn{2}{|c|}{$K_{s}\left(\mathrm{~N} \mathrm{~m} \mathrm{rad}{ }^{-1}\right)$} & \multicolumn{3}{|c|}{$\omega_{1}\left(\operatorname{rad~s}^{-1}\right)$} & \multicolumn{3}{|c|}{$\omega_{2}\left(\operatorname{rad~s}^{-1}\right)$} & \multicolumn{3}{|c|}{$\omega_{3}\left(\operatorname{rad~s}^{-1}\right)$} \\
\hline & Present & {$[15]$} & Present & [9] & [15] & Present & [9] & {$[15]$} & Present & [9] & [15] \\
\hline 0 & $4.8 \mathrm{E} 6$ & - & 1038.29 & 1037.01 & 1038.2 & 6510.28 & 6458.34 & 6506.3 & 18459.94 & 17960.56 & 18218 \\
\hline 0.2 & 113045 & 130000 & 1028.342 & 1020.13 & - & 6509.69 & 6457.39 & - & 18403.70 & 17872 & - \\
\hline 0.4 & 38380 & 28800 & 1009.40 & 966.9 & - & 6508.60 & 6454.48 & - & 18297.65 & 17596.57 & - \\
\hline 0.6 & 16200 & 8400 & 973.1 & 842.2 & - & 6506.55 & 6448.175 & - & 18098.13 & 16944 & - \\
\hline
\end{tabular}

Table 4 Natural frequencies of a cantilever beam with a single crack located at a distance $\xi=0.2 \mathrm{~L}$

\begin{tabular}{|c|c|c|c|c|c|c|c|c|c|c|c|}
\hline \multirow{2}{*}{$d_{c r} / h$} & \multicolumn{2}{|c|}{$K_{s}\left(\mathrm{~N} \mathrm{~m} \mathrm{rad}{ }^{-1}\right)$} & \multicolumn{3}{|c|}{$\omega_{1}\left(\mathrm{rad} \mathrm{s}^{-1}\right)$} & \multicolumn{3}{|c|}{$\omega_{2}\left(\operatorname{rad~s}^{-1}\right)$} & \multicolumn{3}{|c|}{$\omega_{3}\left(\mathrm{rad} \mathrm{s}^{-1}\right)$} \\
\hline & Present & [15] & Present & [9] & {$[15]$} & Present & [9] & {$[15]$} & Present & [9] & {$[15]$} \\
\hline 0 & $4.8 \mathrm{E} 6$ & - & 1038.29 & 1037.01 & 1038.2 & 6510.28 & 6458.34 & 6506.3 & 18459.94 & 17960.56 & 18218 \\
\hline 0.2 & 113045 & 130000 & 1034.14 & 1030 & 1034.6 & 6468.20 & 6389 & 6469.6 & 18381.53 & 17844 & 18152 \\
\hline 0.4 & 38380 & 28800 & 1026.30 & 1006.85 & 1022.2 & 6391.01 & 6174.54 & 6348.9 & 18241.21 & 17499.83 & 17942 \\
\hline 0.6 & 16200 & 8400 & 1010.35 & 942.73 & 985.98 & 6243.21 & 5689.73 & 6036.0 & 17984.96 & 16792.25 & 17447 \\
\hline
\end{tabular}

Table 5 Natural frequencies of a cantilever beam with a single crack located at a distance $\xi=0.4 L$

\begin{tabular}{|c|c|c|c|c|c|c|c|c|c|c|c|}
\hline \multirow{2}{*}{$d_{c r} / h$} & \multicolumn{2}{|c|}{$K_{s}\left(\mathrm{~N} \mathrm{~m} \mathrm{rad}^{-1}\right)$} & \multicolumn{3}{|c|}{$\omega_{1}\left(\mathrm{rad} \mathrm{s}^{-1}\right)$} & \multicolumn{3}{|c|}{$\omega_{2}\left(\operatorname{rad~s}^{-1}\right)$} & \multicolumn{3}{|c|}{$\omega_{3}\left(\operatorname{rad~s}^{-1}\right)$} \\
\hline & Present & [15] & Present & [9] & [15] & Present & [9] & [15] & Present & [9] & [15] \\
\hline 0 & $4.8 \mathrm{E} 6$ & - & 1038.29 & 1037.01 & 1038.2 & 6510.28 & 6458.34 & 6506.3 & 18459.94 & 17960.56 & 18218 \\
\hline 0.2 & 113045 & 130000 & 1037.28 & 1035.28 & 1037.3 & 6454.74 & 6365.91 & 6419.0 & 18362.49 & 17807.94 & 18,137 \\
\hline 0.4 & 38380 & 28800 & 1035.27 & 1029.262 & 1034.2 & 6348.50 & 6071.655 & 6292.3 & 18183.08 & 17359.27 & 17,879 \\
\hline 0.6 & 16200 & 8400 & 1031.12 & 1010.86 & 1024.4 & 6144.14 & 5371.80 & 5852.0 & 17862.20 & 16478.82 & 17,276 \\
\hline
\end{tabular}

Table 6 Natural frequencies of a cantilever beam with a single crack located at a distance $\xi=0.6 L$ 
The obtained results illustrated in Tables 4 to 6 and Figs. 6 to 8 show that the effect of cracking on the frequency of different modes of the structure is different, and the development of a crack at $\zeta=0.2 \mathrm{~L}$ had the greatest effect on the first mode frequency and the development of a crack at $\zeta=0.4 \mathrm{~L}$ and $\zeta=0.6 \mathrm{~L}$ had the greatest effect on the second mode natural frequency.

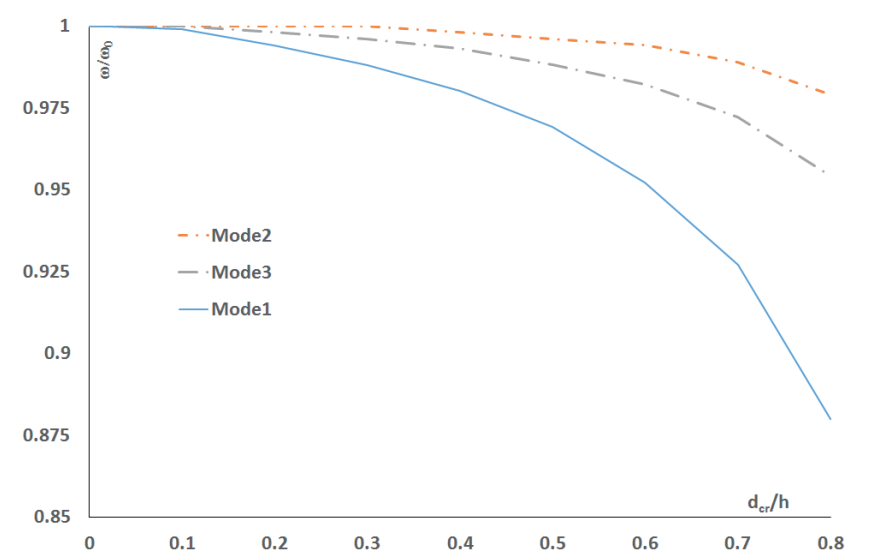

Fig. 6 First three natural frequency Timoshenko beam with different crack depth at $\zeta=0.2 \mathrm{~L}$

Effect of cracking in different points of the beam on the natural frequency of the first mode is shown in Fig. 9. These diagrams show that the cracks near the support of the beam have influence on the natural frequency of the first mode of beam.

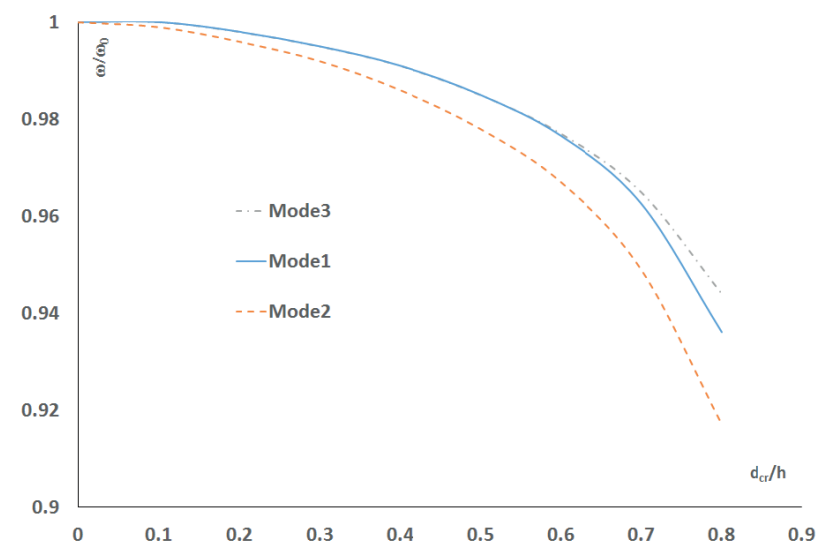

Fig. 7 First three natural frequency Timoshenko beam with different crack depth at $\zeta=0.4 L$

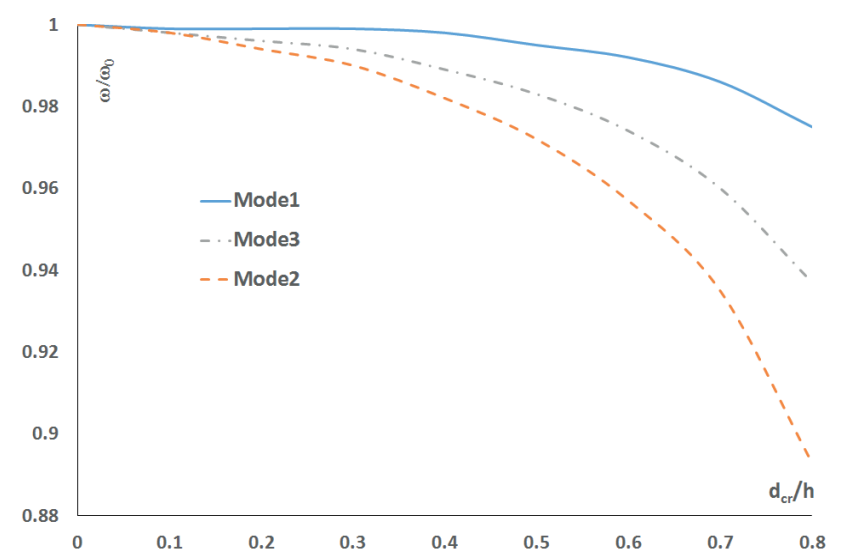

Fig. 8 First three natural frequency Timoshenko beam with different crack depth at $\zeta=0.6 L$

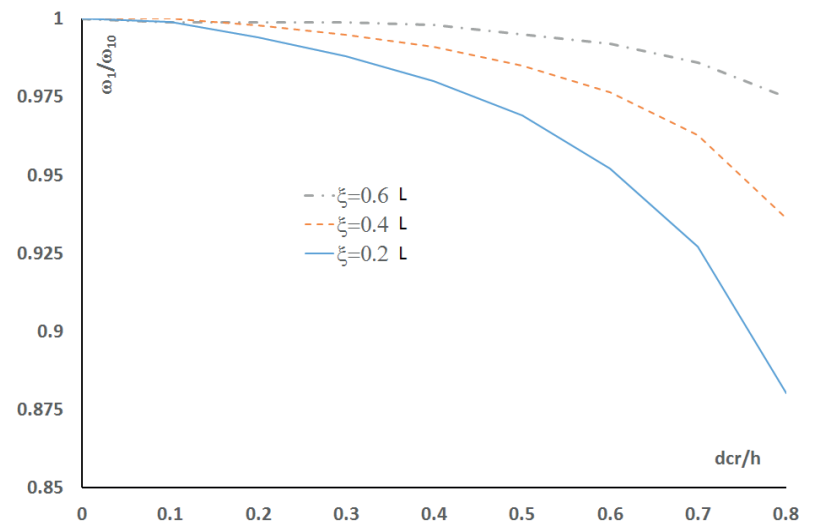

Fig. 9 Natural frequency of first mode in Timoshenko beam with different crack locations

Stiffness of rotational spring equivalent to cracked section obtained using proposed method in the present study were compared with Labib et al. [15] method (Fig. 10).

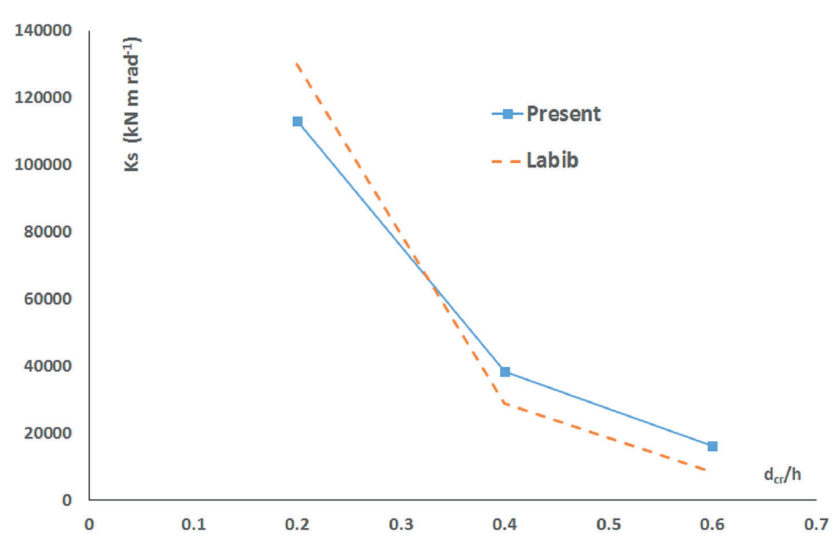

Fig. 10 Stiffness of rotational spring equivalent to cracked section

\section{Natural frequency of a simple support cracked concrete beam}

A finite element model was developed to represent a cracked beam element of length $L$ and the crack was located at a distance $L_{1}$ from the left end of the element as shown in Fig. 1. The element was then split into two segments by the crack. The left and right segments were represented by non-cracked sub elements.

In order to study the effect of cracking on reinforced concrete beams, cracks with different depths in different sections of a concrete beam were created and the natural frequency and mode shapes of the low frequency modes of the vibration were determined. The results of this study are shown in Tables 7 to 8 .

Due to the middle section cracking of the beam, the natural frequency of the first-third mode of the beam decreased. Most of the decreases occurred in the first mode of the beam vibration, while the middle section cracking of the beam had no noticeable influence on the second mode frequency of vibration because the middle section of the beam in the second mode is the turning point of transformation and it acts like a joint. The extent of the natural frequency decrease of the beam, is shown in Fig. 10 and the vibration modes of uncracked and cracked beams, is shown in Fig. 12, respectively. 
Table 7 Rotational spring stiffness equivalent to section and natural frequency of the first-third modes of a simple support concrete beam $L=1000 \mathrm{~mm}, \xi=0.5 \mathrm{~L}, E I=3.32 \mathrm{E} 12 \mathrm{~N} . \mathrm{mm} / \mathrm{rad}, b=150 \mathrm{~mm}, d=200 \mathrm{~mm}$

\begin{tabular}{|c|c|c|c|c|c|c|c|}
\hline \multirow{2}{*}{$d_{c r} / h$} & \multirow{2}{*}{$k_{s}\left(N \mathrm{~mm} \mathrm{rad}^{-1}\right)$} & \multicolumn{2}{|c|}{ Mode1 } & \multicolumn{2}{|c|}{ Mode2 } & \multicolumn{2}{|c|}{ Mode3 } \\
\hline & & $\omega 1$ & $\omega 1 / \omega 10$ & $\omega 2$ & $\omega 2 / \omega 20$ & $\omega 3$ & $\omega 3 / \omega 30$ \\
\hline 0 & $2.91 \mathrm{E}+12$ & 66.885 & 1 & 268.52 & 1 & 612.72 & 1 \\
\hline 0.1 & $1.73 \mathrm{E}+11$ & 65.708 & 0.98 & 268.52 & 1 & 601.63 & 0.98 \\
\hline 0.2 & $6.85 \mathrm{E}+10$ & 63.964 & 0.96 & 268.52 & 1 & 586.41 & 0.96 \\
\hline 0.3 & $3.77 \mathrm{E}+10$ & 61.738 & 0.92 & 268.52 & 1 & 568.88 & 0.93 \\
\hline 0.4 & $2.33 \mathrm{E}+10$ & 59.078 & 0.88 & 268.52 & 1 & 550.36 & 0.9 \\
\hline 0.5 & $1.51 \mathrm{E}+10$ & 55.663 & 0.83 & 268.52 & 1 & 529.85 & 0.86 \\
\hline 0.6 & $9.83 \mathrm{E}+09$ & 51.791 & 0.77 & 268.52 & 1 & 510.24 & 0.83 \\
\hline 0.7 & $6.21 \mathrm{E}+09$ & 46.326 & 0.69 & 268.52 & 1 & 487.78 & 0.8 \\
\hline 0.8 & $3.57 \mathrm{E}+09$ & 39.254 & 0.59 & 268.52 & 1 & 465.59 & 0.76 \\
\hline
\end{tabular}

Table 8 Rotational spring stiffness equivalent to section and the natural frequency of modes of a simple concrete beam $L=1000 \mathrm{~mm}, \xi=0.25 \mathrm{~L}, E I=3.32 \mathrm{E} 12 \mathrm{~N} . \mathrm{mm} / \mathrm{rad}, b=150 \mathrm{~mm}, d=200 \mathrm{~mm}$

\begin{tabular}{|c|c|c|c|c|c|c|c|}
\hline \multirow{2}{*}{$d_{c r} / h$} & \multirow{2}{*}{$k_{s}\left(N \mathrm{~mm} \mathrm{rad}^{-1}\right)$} & \multicolumn{2}{|c|}{ Mode1 } & \multicolumn{2}{|c|}{ Mode2 } & \multicolumn{2}{|c|}{ Mode3 } \\
\hline & & $\omega 1$ & $\omega 1 / \omega 10$ & $\omega 2$ & $\omega 2 / \omega 20$ & $\omega 3$ & $\omega 3 / \omega 30$ \\
\hline 0.01 & $2.91 \mathrm{E}+12$ & 66.885 & 1 & 268.52 & 1 & 612.72 & 1 \\
\hline 0.1 & $1.73 \mathrm{E}+11$ & 66.288 & 0.99 & 263.82 & 0.98 & 607.25 & 0.99 \\
\hline 0.2 & $6.85 \mathrm{E}+10$ & 65.355 & 0.98 & 257.02 & 0.96 & 599.86 & 0.98 \\
\hline 0.3 & $3.77 \mathrm{E}+10$ & 64.132 & 0.96 & 248.96 & 0.93 & 591.86 & 0.97 \\
\hline 0.4 & $2.33 \mathrm{E}+10$ & 62.56 & 0.94 & 239.86 & 0.89 & 583.67 & 0.95 \\
\hline 0.5 & $1.51 \mathrm{E}+10$ & 60.383 & 0.9 & 229.13 & 0.85 & 575.02 & 0.94 \\
\hline 0.6 & $9.83 \mathrm{E}+09$ & 57.638 & 0.86 & 218.05 & 0.81 & 567.05 & 0.93 \\
\hline 0.7 & $6.21 \mathrm{E}+09$ & 53.578 & 0.8 & 205.24 & 0.76 & 558.88 & 0.91 \\
\hline
\end{tabular}

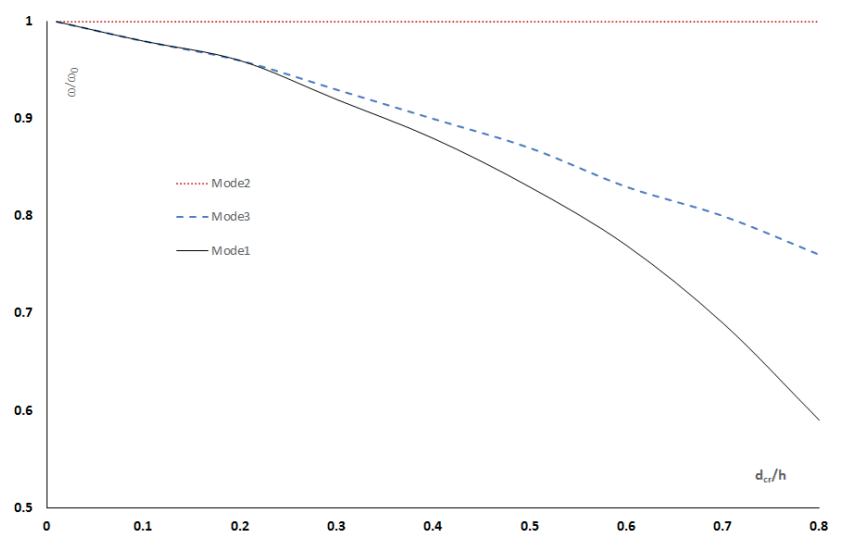

Fig. 11 Natural frequency of the first-third modes of a simple concrete beam with different crack depth in $\zeta=0.5 \mathrm{~L}$

As shown in Fig.11, there is no change in natural frequency of mode two when the crack location was $\zeta=0.5 \mathrm{~L}$ because this location is nodal point of mode two.

The development of a crack in a section of $\zeta=0.25 \mathrm{~L}$ causes a drastic decrease in the natural frequency of the second mode, while it has negligible influence on the frequency of the third mode as shown in Fig. 12. The vibration mode shapes of the beam for a crack depth of $d_{c r}=0.5 h$ is shown in Fig. 14 .

In another example, a two bay beam with multiple singleedge cracks was examined. As shown in Fig. 15, this beam is divided into 14 components by 15 nodes and spring. Therefore,

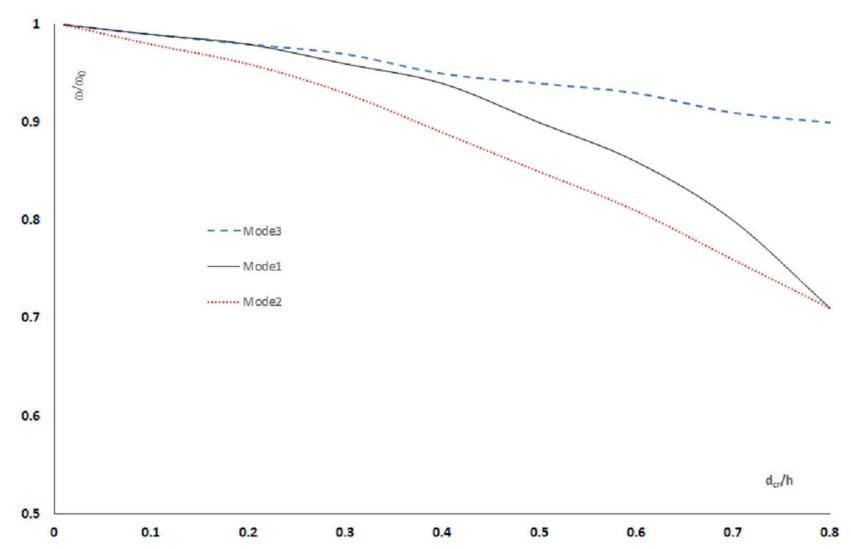

Fig. 12 Natural frequency of the first-third modes of a simple concrete beam at $\zeta=0.25 \mathrm{~L}$

the nonlinear system with a local stiffness discontinuity was divided into several linear subsystems. If uniform damages occur in the beam, the stiffness of all spring will be reduced and natural frequency of beam will change equally for all the modes, as presented in Table 9, but the mode shape of beam will not change as shown in Fig 16.

The first three natural frequencies of a two bay beam (Fig. 15) having a single open crack in each bay, are shown in Table 10. The result shows that if the crack is created at the nodal point location of mode shape, the natural frequency of this mode is not changed. 


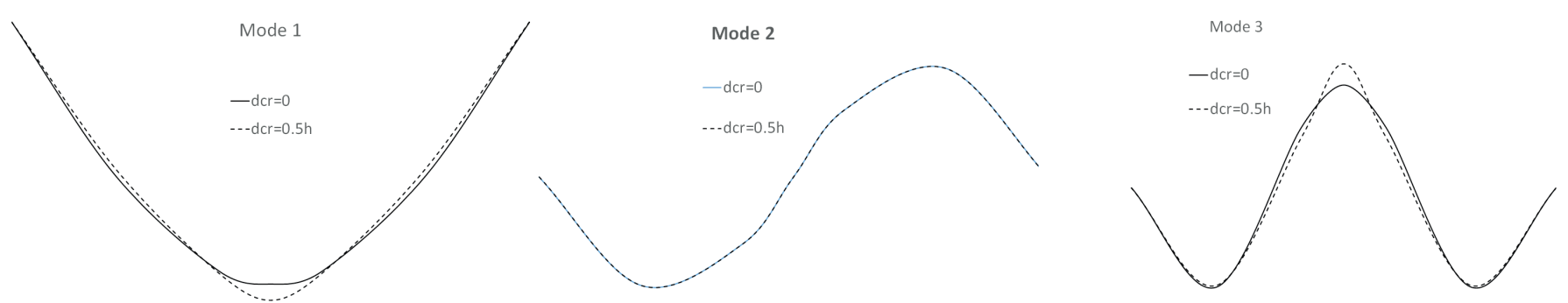

Fig. 13 Mode shapes of an uncracked simple concrete beam and a cracked beam with $d_{c r}=0.5 h, \zeta=0.5 \mathrm{~L}$

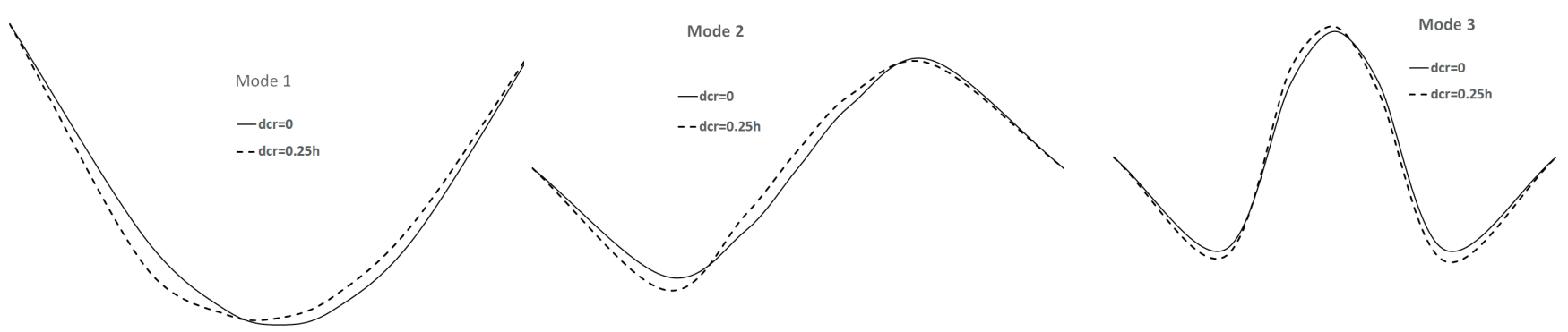

Fig. 14 Mode shapes of an uncracked simple concrete beam and a beam with crack depth of $d_{c r}=0.5 h, \zeta=0.25 \mathrm{~L}$
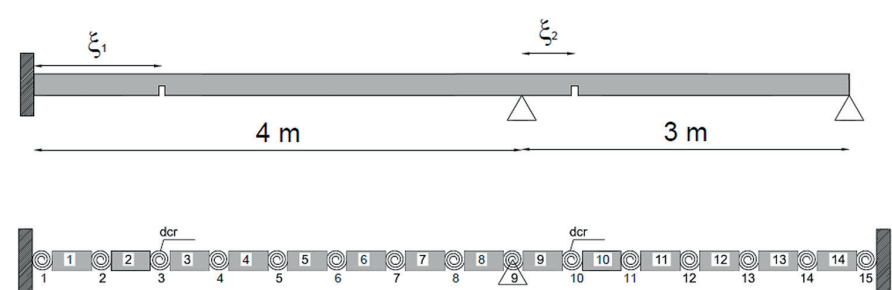

Fig. 15 Two bays beam separated into component and rotational spring
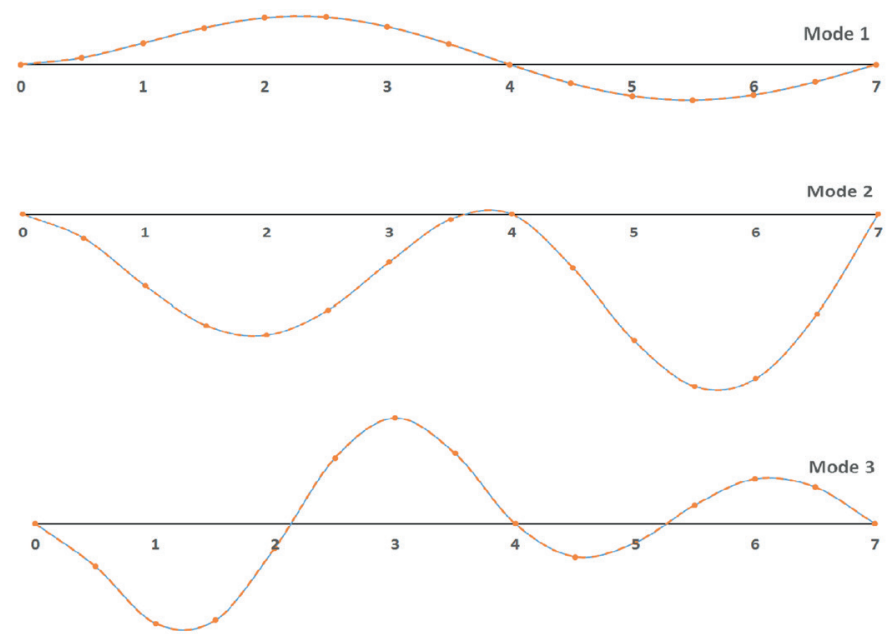

Fig. 16 first three mode of beams with uniform damage

Stiffness matrix of beams can be obtained by a model updating program, if the natural frequency and shape of the beam are determined. The stiffness matrix of the cracked beam, $K$, is then obtained through the assemblage of the intact element stiffness matrices and damage spring stiffness matrix as Eq. 9.

$$
[K]=\left[k_{b}\right]+H I_{n}\left[k_{s 0}\right]
$$

Where $H I_{n}=d_{c r} / h$ is health index of spring equivalent to cracked section $n$, which can be obtained by using an appropriate target function and optimization algorithm, in future research.

\section{Conclusions}

This study presents a new method for calculating the stiffness and natural frequencies of cracked beams. Cracked beams are modelled by simple beams elements and component connected together by pined and massless rotational spring. New method based on strain energy was proposed to obtain the stiffness of rotational spring. Stiffness matrices for beams with multiple cracks were assembled.

In cracked beam, the stiffness of rotational spring equivalent to cracked section is dependent on depth of the crack in section conforming to Eq. 5.

The stiffness of rotational spring equivalent to uncracked section is proportional to the bending rigidity of section proposed in Eq. 8

The effect of cracks on different vibrational modes of cracked beams depended on location of the cracks. There was no effect of crack on the in-plane natural frequency when the crack was located at the nodal points of the mode shape.

\section{References}

[1] Cawley, P., Adams, R. D. "The location of defects in structures from measurements of natural frequencies". The Journal of Strain Analysis for Engineering Design, 14(2), pp. 49-57. 1979. https://doi. org/10.1243/03093247V142049

[2] Gudmundson, P. "Eigenfrequency changes of structures due to cracks, notches or other geometrical changes". Journal of the Mechanics and Physics of Solids, 30(5), pp. 339-353. 1982. https://doi.org/10.1016/00225096(82)90004-7

[3] Chang, H.-Y., Petroski, H. J. "On detecting a crack by tapping a beam". International Journal of Pressure Vessels and Piping, 22(1), pp. 41-55. 1986. https://doi.org/10.1016/0308-0161(86)90043-8

[4] Qian, G.-L., Gu, S.-N., Jiang, J.-S. "The dynamic behaviour and crack detection of a beam with a crack". Journal of Sound and Vibration, 138(2), pp. 233-243. 1990. https://doi.org/10.1016/0022-460X(90)90540-G

[5] Chondros, T. G., Dimarogonas, A. D., Yao, J. "A Continous Cracked Beam Vibration Theory". Journal of Sound and Vibration, 215(1), pp. 17-34. 1998. https://doi.org/10.1006/jsvi.1998.1640 
Table 9 Rotational spring stiffness equivalent to section and the natural frequency of modes of a two bays beam $L=7000 \mathrm{~mm}, E I=5.31 \mathrm{E} 13 \mathrm{~N} . \mathrm{mm}^{2}, b=300 \mathrm{~mm}, d=400 \mathrm{~mm}$

\begin{tabular}{|c|c|c|c|c|c|c|c|c|}
\hline \multirow{2}{*}{$E I\left(N m^{2}\right)$} & \multirow{2}{*}{$E I / E I_{0}$} & \multirow{2}{*}{$\begin{array}{c}k_{s} \\
\left(\mathrm{Nmm} \mathrm{rad}^{-1}\right)\end{array}$} & \multicolumn{2}{|c|}{ Mode1 } & \multicolumn{2}{|c|}{ Mode2 } & \multicolumn{2}{|c|}{ Mode3 } \\
\hline & & & $\omega 1$ & $\omega 1 / \omega 10$ & $\omega 2$ & $\omega 2 / \omega 20$ & $\omega 3$ & $\omega 3 / \omega 30$ \\
\hline $5.30 \mathrm{E}+13$ & 1 & $2.32 \mathrm{E}+13$ & 13.81 & 1 & 21.276 & 1 & 46.38 & 1 \\
\hline $4.24 \mathrm{E}+13$ & 0.8 & $1.86 \mathrm{E}+13$ & 13.801 & 0.999 & 21.262 & 0.999 & 46.347 & 0.999 \\
\hline $2.65 E+13$ & 0.5 & $1.16 \mathrm{E}+13$ & 13.773 & 0.997 & 21.22 & 0.997 & 46.244 & 0.997 \\
\hline $5.30 \mathrm{E}+12$ & 0.1 & $2.32 \mathrm{E}+12$ & 13.485 & 0.976 & 20.786 & 0.977 & 45.188 & 0.974 \\
\hline $4.24 \mathrm{E}+12$ & 0.08 & $1.86 \mathrm{E}+12$ & 13.399 & 0.97 & 20.657 & 0.971 & 44.877 & 0.968 \\
\hline $5.30 \mathrm{E}+11$ & 0.01 & $2.32 \mathrm{E}+11$ & 11.145 & 0.807 & 17.257 & 0.811 & 36.91 & 0.796 \\
\hline
\end{tabular}

Table 10 Rotational spring stiffness equivalent to section and natural frequency of modes of a two bay beam $\xi_{1}=1000 \mathrm{~mm}, \xi_{2}=500 \mathrm{~mm}$

\begin{tabular}{|c|c|c|c|c|c|c|c|}
\hline \multirow{2}{*}{$\frac{d_{c r 1}}{h}$} & \multirow{2}{*}{$\frac{d_{c r 2}}{h}$} & \multicolumn{2}{|c|}{ Mode1 } & \multicolumn{2}{|c|}{ Mode2 } & \multicolumn{2}{|c|}{ Mode3 } \\
\hline & & $\omega 1$ & $\omega 1 / \omega 10$ & $\omega 2$ & $\omega 2 / \omega 20$ & $\omega 3$ & $\omega 3 / \omega 30$ \\
\hline 0 & 0 & 13.81 & 1 & 21.276 & 1 & 46.38 & 1 \\
\hline 0.4 & 0 & 13.81 & 1 & 21.253 & 0.999 & 44.912 & 0.968 \\
\hline 0.6 & 0 & 13.808 & 1 & 21.226 & 0.998 & 43.373 & 0.935 \\
\hline 0 & 0.4 & 13.638 & 0.988 & 21.183 & 0.996 & 45.538 & 0.982 \\
\hline 0 & 0.6 & 13.45 & 0.974 & 21.086 & 0.991 & 44.64 & 0.962 \\
\hline 0.4 & 0.4 & 13.637 & 0.987 & 21.161 & 0.995 & 44.16 & 0.952 \\
\hline 0.6 & 0.6 & 13.446 & 0.974 & 21.044 & 0.989 & 42.013 & 0.906 \\
\hline
\end{tabular}

[6] Papadopoulos, C. A., Dimarogonas, A. D. "Dimarogonas, Coupled longitudinal and bending vibrations of a rotating shaft with an open crack". Journal of Sound and Vibration, 117(1), pp. 81-93. 1987. https://doi. org/10.1016/0022-460X(87)90437-8

[7] Ostachowicz, W. M., Krawczuk, M. "Analysis of the effect of cracks on the natural frequencies of a cantilever beam". Journal of Sound and Vibration, 150(2), pp. 191-201. 1991. https://doi.org/10.1016/0022460X(91)90615-Q

[8] Doebling, S. W., Farrar, C. R., Prime, M. B., Shevitz, D. W. "Damage Identification and Health Monitoring of Structural and Mechanical Systems from Changes in their vibration characteristics". In: LA-13070-MS. University of California: Los Alamos National Laboratory. 1996. https://www. osti.gov/scitech/servlets/purl/249299-n4r7Vr/webviewable/

[9] Kisaa, M., Brandon, J., Topcu, M. "Free vibration analysis of cracked beams by a combination of finite elements and component mode synthesis methods". Computers \& Structures, 67(4), pp. 215-223. 1998. https://doi. org/10.1016/S0045-7949(98)00056-X

[10] Ali, K. A. "Short-Term Deflection And Flexural Rigidity Of Reiforced Concrete Beams". International Journal Of Engineering Science, (15) pp. 1-13. 2004.

[11] Ismail, Z., Abdul Razak, H., Abdul Rahman, A. G. "Determination of damage location in RC beams using mode shape derivatives". Engineering Structures, 28(11), pp. 1566-1573. 2006. https://doi.org/10.1016/j. engstruct. 2006.02.010

[12] Caddemi, S., Caliò, I. "Exact closed-form solution for the vibration modes of the Euler-Bernoulli beam with multiple open cracks". Journal of Sound and Vibration, 327(3-5), pp. 473-489. 2009. https://doi.org/10.1016/j. jsv.2009.07.008

[13] Kaklauskas, G., Gribniak, V., Jakubovskis, R., Gudonis, E., Saliys, D., Kupliauskas, R. "Serviceability Analysis of Flexural Reinforced Concrete Members". Journal of Civil Engineering and Management, 18(1), pp. 24 29. 2012. https://doi.org/10.3846/13923730.2011.643553
[14] Ibrahim, A. M., Ozturk, H., Sabuncu M. "Vibration analysis of cracked frame structures". Structural Engineering and Mechanics, 45(1), pp. $33-$ 52. 2013. https://doi.org/10.12989/sem.2013.45.1.033

[15] Labib, A., Kennedy, D., Featherston, C. "Free vibration analysis of beams and frames with multiple cracks for damage detection". Journal of Sound and Vibration, 333(20), pp. 4991-5003. 2014. https://doi.org/10.1016/j. jsv.2014.05.015

[16] Labib, A., Kennedy, D., Featherston, C. "Crack localisation in frames using natural frequency degradations". Computers \& Structures, 157, pp. 51-59. 2015. https://doi.org/10.1016/j.compstruc.2015.05.001

[17] Aktas, M., Sumer, Y. "Nonlinear finite element analysis of damaged and strengthened reinforced concrete beams". Journal of Civil Engineering and Management, 20(2), pp. 201-210. 2014. https://doi.org/10.3846/13923730 .2013 .801889

[18] Jena, S. P., Parhi, D.R., Mishra, D. "Comparative study on cracked beam with different types of cracks carrying moving mass". Structural Engineering and Mechanics, 56(5), pp. 797-811. 2015. https://doi.org/10.12989/ sem.2015.56.5.797

[19] Akbas, S. D. "Analytical solutions for static bending of edge cracked micro beams". Structural Engineering and Mechanics, 59(3), pp. 579-599. 2016. https://doi.org/10.12989/sem.2016.59.3.579

[20] Eroglu, U., Tufekci, E. "Exat Solution Based Finite Element Formulation of Cracked Beam for Crack Detection". International Journal of Solids and Structures, 96, pp. 240-253. 2016. https://doi.org/10.12989/ sem.2016.59.3.579

[21] Sabuncu, M., Ozturk, H., Yashar, A. "Static and dynamic stability of cracked multi-storey steel frames". Structural Engineering and Mechanics, 58(1), pp. 103-119. 2016. 10.12989/sem. 2016.59.3.579

[22] Lee, J., "Identification of multiple cracks in a beam using natural frequencies". Journal of Sound and Vibration, 2009. 320(3), pp. 482-490. 10.1016/j.jsv.2008.10.033

[23] Wendtland, D. "Anderungen der biegeeigen frequenzen einer idealisierten schaufel durch risse". Ph. D. Thesis. Universitat Karlsruhe (TH). 1972. 